Калиниченко Максим Петрович

\title{
ПРОЕКТИРОВАНИЕ СИСТЕМЫ МАРКЕТИНГ-МЕНЕДЖМЕНТА И ОРИЕНТИРОВАННОЙ НА РЫНОК ОРГАНИЗАЦИОННОЙ СТРУКТУРЫ ПРЕДПРИЯТИЯ
}

\begin{abstract}
В статье представлены результаты исследования научно-методических, методологических и практических подходов к проектированию ориентированных на рынок систем и организационных структур управления. Разработан проект «Проектирование системы маркетинг-менеджмента ООО «НПО „Донвентилятор" ", проведен опрос руководителей предприятий на предмет используемых форм организационных структур управления, а также опрос персонала на предмет готовности к организационным изменениям. Оиенка существуюиих организационных структур управления ООО «НПО „Донвентилятор"» и ПАО «Снежнянскхиммаи» позволила установить их сильные, слабые стороны и получить результаты для разработки проекта по формированию ориентированных на рынок организациониых структур. Также в статье представлен механизи и рекомендации по формированию ориентированных на рынок организационных структур с иелью их системного взаимодействия с системой маркетинг-менеджмента.

Ключевые слова: ориентация на рынок, проектирование системы управления, проектирование структуры управления, маркетинг менеджмент, предприятие, проект.

\section{Maksim Kalynychenko \\ DESIGNING THE MARKETING SYSTEM OF MANAGEMENT \\ AND ORIENTED INTO THE MARKET OF THE ORGANIZATIONAL STRUCTURE OF THE ENTERPRISE}

The article presents the results of research of theoretical, methodological and practical approaches to the design of market-oriented systems and organizational management structures. The project is designed "System design marketing management LLC «SPA „Donventilyator" ", conducted a survey of business leaders for used forms of organizational structures of management and staff survey on the subject of readiness for organizational change. Evaluation of existing organizational structures of management LLC "SPA „Donventilyator"» and PC «Snezhnyanskhimmash» allowed to establish their strengths, weaknesses, and get the results to develop a project for the formation of market-oriented organizational structures. The article presents a mechanism and recommendations for the formation of market-oriented organizational structures with the aim of their systematic interaction with the marketing management system.

Key words: market orientation, management system design, management structure design, marketing management, enterprise, project.
\end{abstract}

Bведение / Introduction. Маркетинг-менеджмент (или маркетинговое управление предприятием, далее МУП) нами рассматривается как одна из форм менеджмента. Объект такого управления - предприятие в целом для достижения его целей за счет обеспечения рыночной ориентации и гармонизации интересов ключевых групп заинтересованных сторон (ГЗС). Такая форма менеджмента требует не только высокой межфункциональной интеграции, но и конвергенции системы МУП и организационной структуры предприятия (ОСП).

В теории и на практике одной из актуальных проблем, возникающих в процессе трансформации системы управления, с одной стороны, и ОСП, с другой стороны, является отсутствие их синхронной динамики и взаимного соответствия. По этой причине возникает актуальная научно-практическая потребность в проектировании ориентированных на рынок систем МУП и ОСП, а также в разработке механизма их системного взаимодействия. 
Цель исследования состоит в обобщении научно-практических и методологических подходов к проектированию рыночно ориентированных систем МУП и ОСП, в разработке механизма их системного взаимодействия.

Maтериалы и методы / Materials and methods. В 1962 г. А. Д. Чандлер первым поставил вопрос об «организационном соответствии» предприятия задачам стратегического управления, сформулировал идею: ориентация на определенные стратегические цели должна определять выбор адекватной ОСП [1]. Несмотря на многолетний зарубежный и отечественный опыт проектирования ОСП, в методологическом плане система организационного проектирования, в том числе с ориентацией на рынок, не сформировалась как целостная концепция, которая бы включала понятийный аппарат, принципы, базовый инструментарий, базовые алгоритмы. Проблемам выбора формы ОСП, проведения организационных изменений и проектирования посвящены работы целого ряда зарубежных и отечественных авторов. Вопросы формирования ориентированных на рынок ОСП поднимали О. С. Виханский [2], Дж. Дей [3], Ж.-Ж. Ламбен [4] и др. На сегодняшний день разработаны методы построения ОСП, которые можно использовать для проектирования ориентированных на рынок ОСП [5]. В ряде исследований авторы представили классификацию методов или разработали методические подходы, которые будут использованы для диагностики ОСП [6-8].

Pезультаты и обсуждение / Results and discussion. Наши результаты исследований показывают, что формирование систем МУП может осуществляться на основе двух методологических подходов: улучшение и проектирование. Первый подход связан с процессом преобразований и изменений, направлен на исключение отклонений от установленного порядка работы и ускорение движения предприятия к условиям «как должно быть» (для этого требуется стратегия, план, нормативы показателей и т. д., по которым можно проводить сравнение). Второй подход также связан с процессом преобразований и изменений, но направлен на изменение структурных факторов, функций, бизнес-процессов и т. д., необходимых для достижения установленных целей управления. Таким образом, проектирование систем МУП от улучшения в корне отличается методологией, целями, масштабом и результатами.

Отправной точкой при проектировании систем МУП должны выступать: новый взгляд на цели предприятия на целевом рынке и производных с ним ресурсных рынках, а также формы взаимодействия с внешней средой и интересы ключевых ГЗС. Основное назначение проектирования системы МУП - сформировать такую систему управления, которая устанавливала бы и поддерживала необходимые связи, по которым и благодаря которым можно осуществлять управляющее воздействие для достижения целей управления.

В качестве входа процесса проектирования системы МУП должны выступать: миссия, цели МУП и стратегии их достижения, общие и специфические законы управления, организации, информация о состоянии внешней среды и т. д. Выходом процесса проектирования системы МУП являются следующие элементы: принципы, критерии, функции, процессы, обеспечивающие подсистемы, методы, структура МУП. Под проектированием системы МУП будем понимать деятельность, направленную на разработку и внедрение проектов создания и совершенствования элементов, подсистем и системы управления в целом с целью повышения эффективности (результативности) их функционирования. Процесс проектирования системы МУП предлагается проводить через соблюдение последовательности этапов: предпроектная подготовка; разработка замысла проекта; оценка вариантов проекта; внедрение проекта. Содержание и основные результаты разработанного проекта представлены в таблице 1.

Как отмечает О. С. Виханский, с развитием рыночных отношений «обнаруживаются серьезные недостатки «дорыночного» подхода к проектированию организации. Спроектированные «стены» между функциями загоняют организационную болезнь - функционализм - вглубь. Эти недостатки мешают организации оптимизироваться в направлении рынка» [2]. 


\section{Содержание и результаты проекта «Проектирование системы маркетинг-менеджмента ООО «НПО "Донвентилятор"»}

\begin{tabular}{|c|c|}
\hline Этап & Содержание и основные результаты \\
\hline $\begin{array}{l}\text { 1. Диагностика действу- } \\
\text { ющей системы управ- } \\
\text { ления }\end{array}$ & $\begin{array}{ll}\text { 1.1. Диагностика действующей системы управления. } \\
\text { 1.2. } \\
\text { 1.3. Оценка организационной готовности к внедрению изменений. } \\
\text { Составление матрицы соответствия элементов управления ООО } \\
\text { 1.4. } \\
\text { РПО „Донвентилятор”» требования системы МУП. } \\
\text { 1.4.1 структуры системы МУП; } \\
\text { 1.4.2 основных функцй управления в рамках системы МУП; } \\
\text { 1.4.3 плана и графика работ по проектированию системы МУП. } \\
\text { Основной результат: подготовка отчета о результатах диагностики системы } \\
\text { управления ООО «НПО „Донвентилятор"». }\end{array}$ \\
\hline $\begin{array}{l}\text { 2. Проектирование систе- } \\
\text { мы МУП }\end{array}$ & $\begin{array}{l}\text { 2.1. Описание элементов системы МУП; } \\
\text { 2.2. Описание процессов МУП; } \\
\text { 2.3. Описание основных и поддерживающих процессов в МУП. } \\
\text { 2.4. Определение организации, порядка и методов проведения работ } \\
\text { по процессам; } \\
\text { 2.5. Разработка методического обеспечения по мониторингу, измерению и } \\
\text { анализу состояния основных процессов. } \\
\text { Основной результат: проект системы маркетингового управления ООО } \\
\text { «ПО, Донвентилятор”». }\end{array}$ \\
\hline $\begin{array}{l}\text { 3. Администрирование } \\
\text { системы МУП }\end{array}$ & $\begin{array}{l}\text { 3.1. Разработка положения «О системе маркетингового управления ООО } \\
\text { «НПО,„Донвентилятор"» совместно со специалистами и руководителя- } \\
\text { ми предприятия. } \\
\text { 3.2. Утверждение Положения после его обсуждения и согласования. } \\
\text { 3.3. Разработка стандартов предприятия, инструкций, регламентов, в т. ч. в } \\
\text { привязке по элементам системы маркетингового управления. } \\
\text { 3.4. Разработка конкретных нормативно-методических материалов и рабо- } \\
\text { чих документов. } \\
\text { Основной результат: Административное обеспечение внедрения системы } \\
\text { маркетингового управления ООО «НПО, Донвентилятор”». }\end{array}$ \\
\hline $\begin{array}{l}\text { 4. Обучение и проведение } \\
\text { тренингов для управ- } \\
\text { ленческих кадров }\end{array}$ & $\begin{array}{l}\text { 4.1. Проведение семинаров и тренингов по вопросам разработки, внедрения, } \\
\text { диагностики и администрирования системы МУП. } \\
\text { 4.1. Семинар для управленческих кадров ООО «НПО „Донвентилятор”»: } \\
\text { «Содержание, преимущества и основные элементы системы МУП»; } \\
\text { 4.2. Семинар и тренинг для управленческих кадров ООО «НПО „Донвенти- } \\
\text { лятор”»: «Организационная готовность к внедрению изменений». } \\
\text { Основной результат: наличие подготовленных и мотивированных управ- } \\
\text { ленческих кадров в ООО «НПО,Донвентилятор”. }\end{array}$ \\
\hline $\begin{array}{l}\text { 5. Внедрение системы } \\
\text { МУП }\end{array}$ & $\begin{array}{l}\text { 5.1. Реинжиниринг бизнес-процессов ООО «НПО „Донвентилятор”»; } \\
\text { 5.2. Изменение структуры управления ООО «НПО „Донвентилятор”»; } \\
\text { 5.3. Совершенствование взаимодействия бизнес-процессов. } \\
\text { Основной результат: повышение рыночной ориентации и удовлетворен- } \\
\text { ности ключевых ГЗС, а также повышение экономической эффективности } \\
\text { деятельности ООО «НПО „Донвентилятор”». }\end{array}$ \\
\hline $\begin{array}{l}\text { 6. Экспресс-анализ систе- } \\
\text { мы МУП }\end{array}$ & $\begin{array}{l}\text { Проведение экспресс-анализа для установления соответствия положению } \\
\text { «О системе маркетингового управления ООО «НПО „Донвентилятор"». } \\
\text { Основной результат: подтверждение соответствия Положению. }\end{array}$ \\
\hline
\end{tabular}

Дж. Дэй среди составляющих рыночной ориентации выделял следующие: внешне ориентированная культура; способность чувствовать рынок и устанавливать с ним связи и прогностическое стратегическое мышление; конфигурация. Конфигурация предполагает фокусирование на более ценных для организации покупателях; согласованность структуры и систем управления (достигается тогда, когда все элементы организации - культура, способности и конфигурация - 
дополняют и поддерживают друг друга); способность к адаптации или гибкость (необходимо разработать структуру, способную сочетать в себе глубину знания, имеющегося у вертикальной иерархии, со способностью быстрого реагирования, которой обладают группы, осуществляющие горизонтальные процессы) [3].

Дж. Дэй делится своим опытом: «... даже самые искренние попытки сориентировать ОСП на рынок могут оказаться безрезультатными; не существует идеального проекта для всех ситуаций (любой проект является результатом многих компромиссов, не обязательно удовлетворяющим все стороны). При этом возникают дилеммы ...» (таблица 2) [3].

Таблица 2

\section{Дилеммы при проектировании рыночно-ориентированных ОСП}

\begin{tabular}{|c|c|c|}
\hline Посылка дилеммы & & Разделительное суждение \\
\hline $\begin{array}{l}\text { Сохранение гибкости поведения за счет исполь- } \\
\text { зования небольших организационных единиц }\end{array}$ & или & Достижение экономии за счет эффекта масштаба \\
\hline $\begin{array}{l}\text { Приведение ОСП в соответствие с рынком и } \\
\text { условиями географических территорий }\end{array}$ & или & $\begin{array}{l}\text { Развитие и использование отличительных спо- } \\
\text { собностей }\end{array}$ \\
\hline Новизна и инновационность & или & Предсказуемость и постоянство \\
\hline $\begin{array}{l}\text { Выработка собственного глубоко опыта осу- } \\
\text { ществления функций }\end{array}$ & или & $\begin{array}{l}\text { Подчинение функционирующих подразделений } \\
\text { группам, осуществляющим процесс }\end{array}$ \\
\hline Облегчение координации и обмен ил & или & $\begin{array}{l}\text { Исключение побочных и непродуктивных ви- } \\
\text { дов деятельности }\end{array}$ \\
\hline
\end{tabular}

Профессор Ж.-Ж. Ламбен рассматривает межфункциональную координацию как всеобщее дело коллектива предприятия, а не прерогативу специалистов по маркетингу; как организационный фактор, объединяющий все структурные уровни организации и образующий культуру рыночной ориентации (рис. 1). Межфункциональная координация делает возможными коммуникацию и обмен между разными отделами, так или иначе соприкасающимися с отдельными или всеми четырьмя рыночными группами влияния: потребители, конкуренты, дистрибьюторы, влиятельные лица [4].

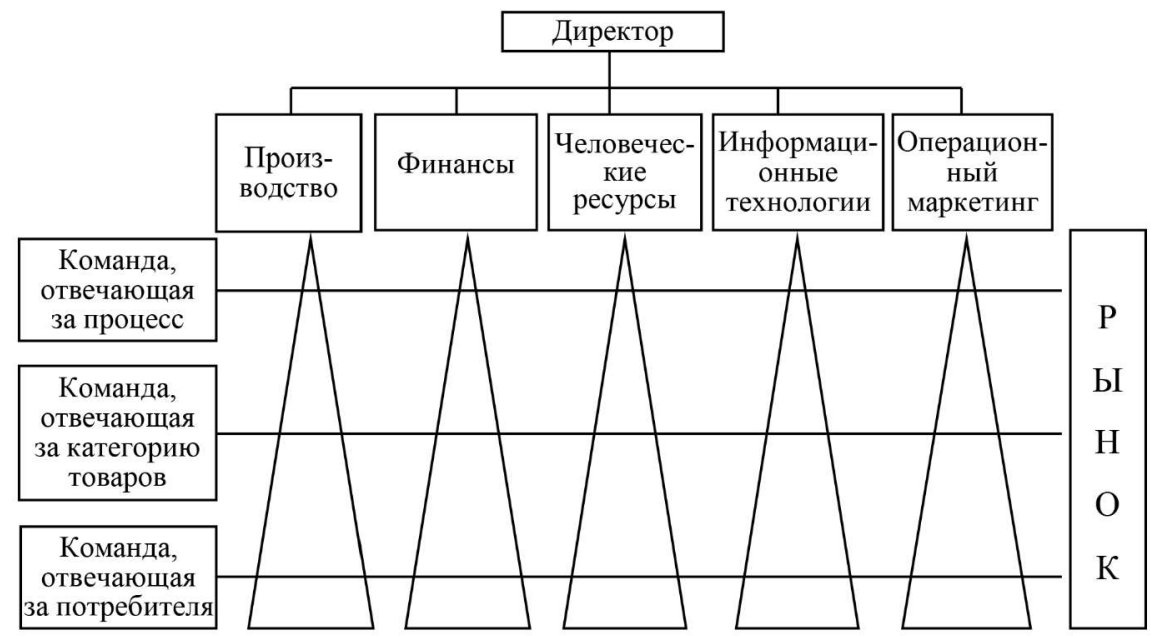

Рис. 1. Организация ориентированного на рынок предприятия [4]

О. С. Виханский ориентированное на рынок предприятие рассматривает как комбинацию эдхократических, многомерных, партисипативных и предпринимательских организаций и описывает следующим образом: «... по характеру взаимодействия с рынком - это органический тип 
организации, быстро адаптирующийся к происходящим вовне изменениям. По характеру взаимодействия частей внутри организации - это либо развитая дивизиональная, либо реальная матричная структура. Принципиальное отличие в том, что в данном случае речь идет о группировании всех частей организации вокруг рынка или рынков». Система управления становится главным ресурсом предприятия. Все в организации направлено на сближение тех, кто принимает решение, с теми, кто это решение покупает, - потребителями. По мнению автора, структура рыночно ориентированной организации меняется в следующих направлениях: связи в структуре организации формируются больше под воздействием отношений организации с потребителями (процессы), а не отношений между функциями (рис. 2) [2].

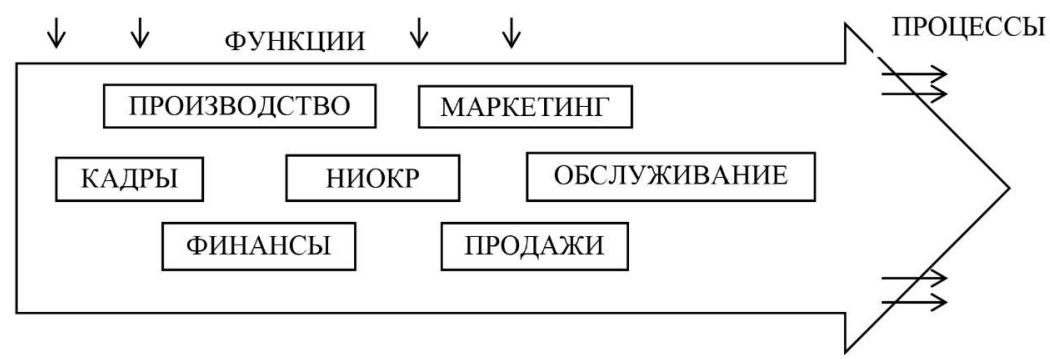

Рис. 2. Рыночная ориентация в группировании частей организации (от «функции») к «процессам») [2]

Организация проектируется исходя из потребностей потребителя, вместо жесткой иерархии возникают достаточно автономные группы, которым придается статус «центра прибыли» или бизнес-группы (рис. 3).

$$
\begin{aligned}
& 1 \text { - руководство } \\
& 2 \text { - проектные группы/ } \\
& \text { рабочие ячейки }
\end{aligned}
$$

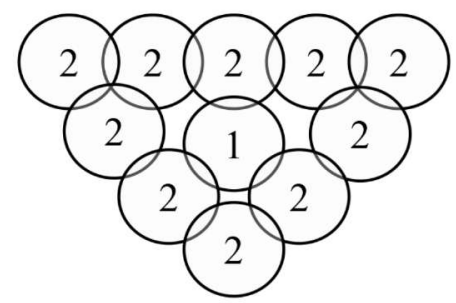

Рис. 3. Матричный и органический подходы к дифференцированию организации [2]

Сами группы, в которых все отвечают за все, функционируют в рамках закрепленного за

\begin{tabular}{|c|c|c|c|c|c|c|}
\hline $\begin{array}{c}\text { Снабже- } \\
\text { ние }\end{array}$ & НИОКР & $\begin{array}{l}\text { Произ- } \\
\text { водство }\end{array}$ & Маркетинг & Продажи & $\begin{array}{c}\text { Обслу- } \\
\text { живание }\end{array}$ & $\begin{array}{l}\text { выполнение } \\
\text { процесса }\end{array}$ \\
\hline
\end{tabular}
ними процесса. Образуется сетевая схема ОСП (рис. 4).

Рабочая группа

Рис. 4. Сетевая форма ОСП [2]

Перед тем как приступить к проектированию ориентированной на рынок ОСП необходимо провести диагностику существующей ОСП, так как ее недостатки могут выступать в качестве препятствий диффузии ориентированной на рынок системы МУП и преимушеств новой ОСП. 
В этой связи необходимо установить: степень соответствия системы управления и ОСП; степень готовности персонала к изменениям; первопричины, сдерживающие развитие предприятия и его функциональных подразделений; преимущества и недостатки действующей системы мотивации, квалификации персонала и его способность внедрять мероприятия. После этого можно будет вести речь о разработке рекомендаций по совершенствованию или проектированию системы и ОСП, определять их приоритеты и последовательность действий.

Как показал наш опрос руководителей промышленных предприятий Донбасса (выборка составила 95 предприятий), в основном доминируют линейно-функциональные ОСП (87\%), которые, кстати, наиболее эффективны в стабильной среде и которые трансформируются в большей степени под влиянием следующих причин: изменение организационно-правовой формы предприятия (93\%); изменение целей предприятия и управления (61 \%); изменение конъюнктуры на целевом рынке (54\%). Также большинство респондентов ответили, что считают организационные структуры своих предприятий слабоуправляемыми (57\%), а что ОСП в целом не являются гибкими в отношении интересов потребителей $-32 \%$.

На примере ООО «НПО „Донвентилятор”» (далее «Донвентилятор») и ПАО «Снежнянскхиммаш» (далее «Снежнянскхиммаш») анализ показывает, что используются линейно-функциональные ОСП. Для проведения структурного анализа эти ОСП были представлены в виде графа, для описания их были построены матрицы смежности. Далее была проведена диагностика в соответствии с алгоритмом, описанным в [8]:

1. Установка ранга каждого элемента по матрице смежности. Для «Донвентилятор» наиболее высокие ранги имеет шестой элемент $(0,13)$ - главный инженер и первый элемент структуры $(0,1)$ - директор. Для «Снежнянскхиммаш» наиболее высокие ранги в ОСП имеют директор (первый элемент) - 0,14 и главный инженер (пятый элемент) - 0,13. Чем выше ранг элемента, тем более сильно он связан с другими элементами и от качества его функционирования зависит эффективность системы МУП и ОСП.

2. Проверка связности ОСП. Расчёты показали, что для «Донвентилятор» его ОСП является несвязной, а для «Снежнянскхиммаш» - связной.

3. Оценка структурной избыточности $(\mathrm{R})$. Для «Донвентилятор» $\mathrm{R}=-0,042$ (ОСП несвязная), а для «Снежнянскхиммаш» $\mathrm{R}=0,34$ (ОСП имеет избыточность).

4. Определение неравномерности распределения связей $\mathrm{E}$ (показатель характеризует недоиспользование возможностей ОСП в достижении максимальной связности) и Еотн. Для «Донвентилятор» $\mathrm{E}=7,02$, а для «Снежнянскхиммаш» $\mathrm{E}=13,92$, Еотн $=0,35$. Эта величина для различных типов ОСП изменяется от 0 (для ОСП с равномерным распределением связей) до 1. Расчеты показывают, что для «Снежнянскхиммаш» среднее распределение связей в ОСП (рис. 5).

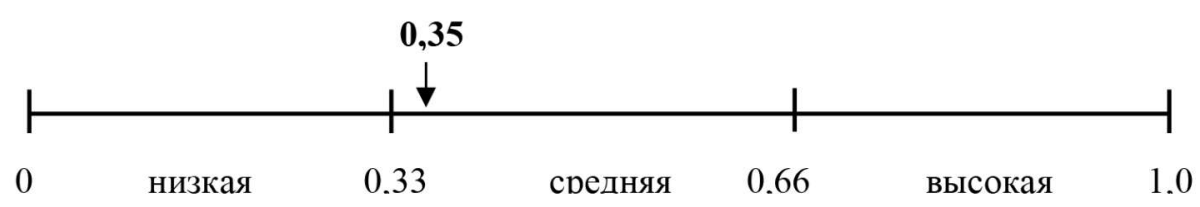

Рис. 5. Шкала для оценивания неравномерности распределения связей в ОСП «Снежнянскхиммаш»

5. Определение структурной компактности ОСП (Q), которая отражает общую структурную близость элементов между собой. На этом этапе диагностики была построена матрица расстояний. Для «Донвентилятор» $\mathrm{Q}=2186$, а для «Снежнянскхиммаш» $\mathrm{Q}=5020$. Для количественной оценки структурной компактности и возможности объ- 
ективного сравнения различных ОСП чаще используют относительный показатель (QОTH). Для «Донвентилятор» $\mathrm{Q}_{\min }=600$, а для «Снежнянскхиммаш» $\mathrm{Q}_{\min }=1482$. Тогда для «Донвентилятор» $\mathrm{Q}_{\text {отн }}=2,64$, а для «Снежнянскхиммаш» $-2,39$. На основе расчета показателей компактности у «Донвентилятор» ОСП менее компактна, чем у «Снежнянскхиммаш».

Также компактность ОСП оценивают через диаметр структуры (d = maxdij), которая равна максимальному значению расстояния $\mathrm{d}_{\mathrm{ij}}$ в матрице расстояний. Для «Донвентилятор» $\mathrm{d}=7$, a для «Снежнянскхиммаш» $\mathrm{d}=6$. Следовательно, предприятия имеют неудовлетворительную компактность своих ОСП.

6. Для характеристики степени централизации ОСП рассчитывается показатель центральности структурного элемента, который характеризует степень удаленности і-го элемента от других элементов ОСП. Для «Донвентилятор» и «Снежнянскхиммаш» наиболее центральным является первый элемент (директор), т. е. он обладает максимальным коэффициентом центральности.

Степень центральности в ОСП в целом может быть охарактеризована индексом центральности $(\delta)$. На основе расчетов для «Донвентилятор» и «Снежнянскхиммаш» показатель центральности ОСП имеет значения 0,80 и 0,86 соответственно. Из этого следует, что предъявляются высокие требования к пропускной способности центра (элемент 1), через который устанавливается и поддерживается большое число связей по приему и переработке информации (рис. 6).

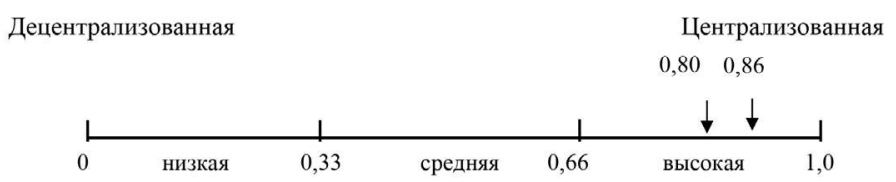

Рис. 6. Шкала для оценивания степени центральности ОСП

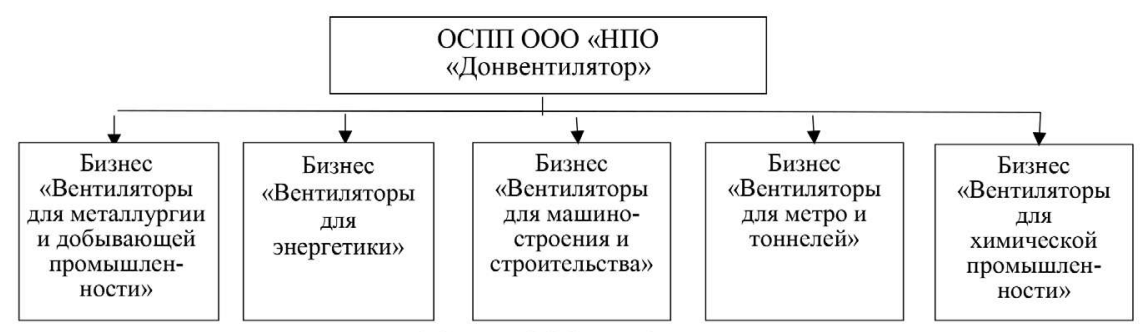

а) Фрагмент ОСП для ООО «НПО «Донсентилятор»

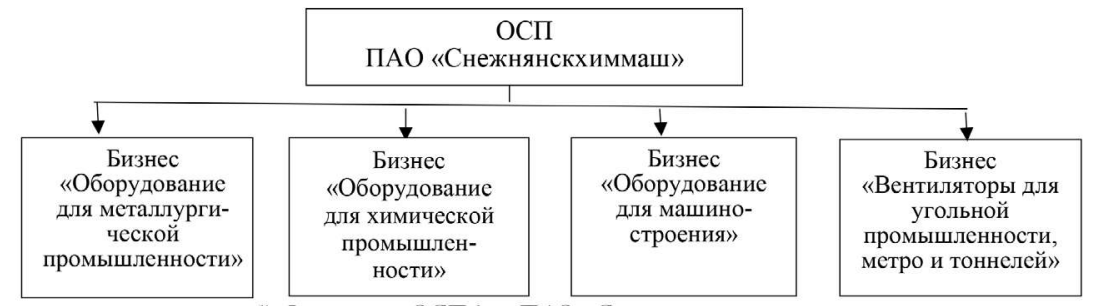

б) Фрагмент ОСП для ПАО «Снеясиянскхиммаи»

Рис. 7. Ориентированные на рынок ОСП после реализации проекта

Диагностика действующих ОСП «Донвентилятор» и «Снежнянскхиммаш» позволила установить, что фактическое число уровней линейного управления превышает научно необходимое, что в том числе подтверждает целесообразность проводимой работы (проектирование с учетом 
сокращения избыточных уровней). Избыточность уровней управления для «Донвентилятор» и «Снежнянскхиммаш» установлена в структуре главного инженера. Компактность ОСП исследуемых предприятий имеет надежность низкого порядка, что отражается на возрастании времени, необходимого для обмена информацией между функциональными подразделениями и снижению оперативности принимаемых управленческих решений. Также проведенная диагностика ОСП подтвердила объективную необходимость не только в том, чтобы внести в них изменения, но и в том, чтобы повысить рыночную ориентацию за счет межфункциональной координации, а также более корректного упорядочения и администрирования: функций, сфер ответственности, компетенции, процедур принятия решений и т. д. Из этого следует, что необходимо незамедлительно совершенствовать или проектировать ОСП. Для «Донвентилятор» (рис. 7а) и «Снежнянскхиммаш» (рис. 7б) разработаны рыночно ориентированные ОСП.

Как было указано выше, при формировании ориентированных на рынок ОСП возникает необходимость оценки психологической готовности персонала к организационным изменениям. Нельзя обойти вниманием факт того, что результаты исследования М. Хаммера и Дж. Чампи указывают, что от 50 до 70 \% инициатив по внедрению организационных изменений заканчиваются провалами из-за недостаточной фокусировки их инициаторов на бизнес-процессах, игнорирования ценностей и убеждений сотрудников, не учета особенностей организационной культуры, слабой компетентности лидеров, высокого сопротивления работников, неточной оценки временного ресурса и т. п. [9].

Результаты исследования Д. Холта, А. Арменакиса и Б. Вайнера, Х. Амик позволили установить, что имеет место теоретическая и концептуальная неоднозначность понятия «готовность» и низкая степень научной обоснованности существующих методов ее оценки [10]. В исследовании Е. А. Наумцевой было проведено обобщение различных теоретических подходов к изучению готовности к организационным изменениям, формирующие различное понимание самого феномена готовности, а также методический инструментарий, применимый в контексте проектирования, внедрения и мониторинга организационных изменений [11].

На основе методики «Организационная готовность к внедрению изменений» (ORIC) К. Ши, С. Якобса, Д. Эссермана была проведена оценка готовности персонала «Донвентилятор» и «Снежнянскхиммаш» к организационным изменениям. Результаты показали, что изменения, связанные с реорганизацией системы управления и ОСП с ориентацией на рынок ожидаемы в большей степени на уровне управленческого персонала (руководители - 81 \% и специалисты $73 \%$ ), а в меньшей степени на уровне производственного персонала (основные - 52 \% и вспомогательные рабочие - $31 \%$ ).

Далее проводилась оценка согласованности действий персонала методом интервью, которая означает отсутствие противоречий между тем, как сам индивид понимает свои функциональные обязанности и тем, как их понимают его прямые руководители и коллеги. Был установлен удельный вес единства мнений с точки зрения того как описывает свои функциональные обязанности индивид и тем, как представляют его же обязанности прямые руководители и коллеги. В «Донвентилятор» к интервью были приглашены 26 чел. или $10 \%$ от среднесписочной численности персонала, в «Снежнянскхиммаш» - 37 чел. или 10 \%. (таблица 3. .).

Таблица 3

Результаты оценки согласованности действий персонала предприятий

\begin{tabular}{|l|c|c|c|c|}
\hline \multirow{2}{*}{ Категория персонала } & \multicolumn{2}{|c|}{ «ПО «Донвентилятор» } & \multicolumn{2}{|c|}{ ПАО «Снежнянскиммапџ } \\
\cline { 2 - 5 } & чел. & $\begin{array}{c}\text { уд. вес согласован- } \\
\text { ности, \% }\end{array}$ & чел. & $\begin{array}{c}\text { уд. вес согласован- } \\
\text { ности, \% }\end{array}$ \\
\hline Руководители & 3 & 0,94 & 4 & 0,87 \\
\hline Специалисты & 7 & 0,73 & 10 & 0,89 \\
\hline
\end{tabular}




\begin{tabular}{|c|c|c|c|c|}
\hline \multirow[b]{2}{*}{ Категория персонала } & \multicolumn{2}{|c|}{ «НПО «Донвенти.лятор» } & \multicolumn{2}{|c|}{ ПАО «Снежнянскхиммаш» } \\
\hline & чел. & $\begin{array}{c}\text { уд. вес согласован- } \\
\text { ности, \% }\end{array}$ & чел. & $\begin{array}{c}\text { уд. вес согласован- } \\
\text { ности, \% }\end{array}$ \\
\hline Основные рабочие & 11 & 0,52 & 19 & 0,65 \\
\hline Вспомогательные рабочие & 5 & 0,36 & 4 & 0,28 \\
\hline Всего & 26 & 0,7 & 37 & 0,71 \\
\hline
\end{tabular}

Среднеарифметическое значение согласованности действий персонала на рассматриваемых промышленных предприятий показывает: «Донвентилятор» и «Снежнянскхиммаш» имеют достаточные значения этих показателей, следовательно, выше вероятность благоприятного исхода для начала реализации проектов по формированию ориентированных на рынок ОСП.

На практике имеют место ситуации, при которых интересы функциональных подразделений вступают в конфликтное противостояние, или персонал вступает в борьбу друг против друга при выполнении определенных функций и задач. Не менее сложной является ситуация, когда никто не берет на себя ответственности и не принимает решений. Поэтому для рассматриваемых предприятий был использован матричный метод распределения ответственности за реализацию основных функций МУП при формировании ОСП.

Таким образом, для реализации проекта новые их ОСП не являются оптимальными, но имеют ряд преимуществ по сравнению с предшествующими. После реализации проекта по формированию ориентированных на рынок ОСП «Донвентилятор» и «Снежнянскхиммаш» звенья управления ОСП могут стать более интегрированными, повысится межфункциональная координация, а сама ОСП будет содержать на порядок меньше избыточных связей между элементами. Распределение связей в новых ОСП можно считать равномерным. Для «Донвентилятор» $(\mathrm{d}=6)$ и для «Снежнянскхиммаш» $(\mathrm{d}=5)$ диаметр новых ОСП снизится. Прежние ОСП были перегружены связями с максимальной удаленностью функциональных подразделений. Матрица расстояний $\mathrm{D}$ в спроектированных ОСП отображает снижение затрат времени. Также произойдет сокращение централизованности новых ОСП

Диффузия ориентированной на рынок модели управления требует, чтобы система МУП и ОСП корреспондировались между собой через механизм их системного взаимодействия и администрирование для повышения гибкости, соответствия друг другу. Другими словами, предприятия, которые ступают на путь маркетинговой реструктуризации систем управления, сталкиваются с научно-практической проблемой - отсутствием эффективного механизма системного взаимодействия одновременно трансформирующихся систем МУП и ОСП. Поэтому механизм системного взаимодействия МУП и ОСП будем рассматривать как сложную систему рычагов влияния на процессы МУП, гармонизацию интересов ключевых ГЗС и устранение противоречий между субъектами и объектами (субъектами) МУП, которая строится на установленных по результатам диагностики закономерностях, научных принципах, взаимодействии на относительно долгосрочной основе, действующей на основе администрирования.

Заключение / Conclusion. На основе развития научно-методических и методологических положений разработан алгоритм проектирования системы МУП и проект «Проектирование системы маркетинг-менеджмента предприятия», проведена диагностика организационных структур для функционирующих предприятий и спроектированы новые организационные структуры с ориентацией на рынок. Разработан механизм и рекомендации по системному взаимодействию системы МУП с ориентированной на рынок ОСП за счет повышения гибкости системы управления при сокращении централизации управленческих функций; повышения межфункциональной координации; перераспределения и укрупнения функций управления; реорганизации функциональных подразделений. 


\section{ЛИТЕРАТУРА И ИНТЕРНЕТ-РЕСУРСЫ}

1. Chandler A. D. Strategy and Structure: A Chapter in the History of Industrial Enterprises. Cambridge, Mass, MIT Press, 1962, $463 \mathrm{p}$.

2. Виханский О. С., Наумов А. И. Менеджмент. М.: Экономистъ, 2006. 670 с.

3. Дэй Дж. Организация, ориентированная на рынок: как понять, привлечь и удержать ценных клиентов. М.: ЭКСМО, 2008. 304 c.

4. Ламбен Жан-Жак. Менеджмент, ориентированный на рынок: стратегический и операционный маркетинг. СПб. : Питер, 2004. 800 с.

5. Калиниченко М. П. Проектирование организационной структуры управления предприятием с ориентацией на гармонизацию интересов заинтересованных сторон // Современные вызовы и реалии экономического развития России: материалы V Международной научно-практической конференции. Ставрополь: Фабула, 2018. С. 208-211.

6. Борщ В. И. Аналитический инструментарий оценки эффективности систем управления предприятием в инновационной экономике // Праці Одеського політехнічного університету, 2012. Вип. 2(39). C. $318-325$.

7. Горшкова Л. А. Анализ организации управления. Аналитический инструментарий. М.: Финансы и статистика, 2003. 208 с.

8. Григан А. М. Управленческая диагностика: теория и практика. Ростов-н/Д: Изд-во РСЭИ, 2009. 316 с.

9. Хаммер М., Чампи Дж. Реинжениринг корпорации. Манифест революции в бизнесе. СПб.: Изд-во Санкт-Петербург. ун-та, 1997. 332 с.

10. Weiner B. J., Amick H., Lee S. Conceptualization and measurement of organizational readiness for change: a review of the literature in health services research and other fields // Med Care Res Rev. 2008. № 65. Pp. 379-436.

11. Наумцева Е. А. Психологическая готовность к организационным изменениям: подходы, понятия, методики // Организационная психология. 2016. Т. 6. № 2. С. 55-74.

\section{REFERENCES AND INTERNET RESOURCES}

1. Chandler A. D. Strategy and Structure: A Chapter in the History of Industrial Enterprises. Cambridge, Mass, MIT Press.1962. 463 p.

2. Vikhansky O. S., Naumov A. I. Menedzhment (Management). M.: Ehkonomist, 2006. 670 s.

3. Day J. Organizaciya, orientirovannaya na rynok: kak ponyat', privlech' i uderzhat' cennyh klientov (Marketoriented organization: how to understand, attract and retain valuable customers). M.: Ehksmo. 2008. $304 \mathrm{~s}$.

4. Lambin Jean-Jacques. Menedzhment, orientirovannyj na rynok: strategicheskij i operacionnyj marketing (Market-oriented management: strategic and operational marketing). SPb.: Piter, 2007. $800 \mathrm{~s}$.

5. Kalynychenko M. P. Proektirovanie organizacionnoj struktury upravleniya predpriyatiem s orientaciej na garmonizaciyu interesov zainteresovannyh storon (Designing the organizational structure of enterprise management with the focus on harmonizing the interests of stakeholders) // Sovremennye vyzovy i realii ehkonomicheskogo razvitiya Rossii. Stavropol: Fabula, 2018, S. 208-211.

6. Borsch V. I. Analiticheskij instrumentarij ocenki ehffektivnosti sistem upravleniya predpriyatiem v innovacionnoj ehkonomike (Analytical tools for assessing the effectiveness of enterprise management systems in the innovation economy) // Praci Odes'kogo politekhnichnogo universitetu. 2012. No 2(39). S. 318-325.

7. Gorshkova L. A. Analiz organizacii upravleniya. Analiticheskij instrumentarij (Analysis of management organization. Analytical toolkit). M.: Finansy i statistika, 2003, S. 208.

8. Grigan A. M. Upravlencheskaya diagnostika: teoriya i praktika (Management Diagnostics: Theory and Practice). Rostov-n/D.: RSEI, 2009. $316 \mathrm{~s}$.

9. Hammer M., Champi J. Reinzheniring korporacii. Manifest revolyucii v biznese (Reengineering Corporation. Manifesto of the revolution in business). SPb.: Izd-vo Sankt-Peterburg. un-ta, 1997, $332 \mathrm{~s}$.

10. Weiner B.J., Amick H., Lee S. Conceptualization and measurement of organizational readiness for change: a review of the literature in health services research and other fields // Med Care Res Rev. 2008. No 65. S. 379-436.

11. Naumtseva E.A. Psihologicheskaya gotovnost' k organizacionnym izmeneniyam: podhody, ponyatiya, metodiki (Psychological readiness for organizational changes: approaches, concepts, methods) // Organizacionnaya psihologiya. 2016. No 2. S. 55-74. 


\section{СВЕДЕНИЯ ОБ АВТОРЕ}

Калиниченко Максим Петрович, кандидат экономических наук, доцент, доцент кафедры маркетинга и логистики ГОУ ВПО «Донецкий национальный университет». E-mail: mpk79@mail.ru

\section{INFORMATION ABOUT AUTHOR}

Maksim Kalynychenko, Candidate of Economic Sciences, Associate Professor, Marketing and Logistics department, Donetsk National University. E-mail: mpk79 a)mail.ru

\section{Колесниченко Елена Александровна, Радюкова Яна Юрьевна, Колесниченко Дмитрий Александрович}

\section{СОВЕРШЕНСТВОВАНИЕ ДЕЯТЕЛЬНОСТИ МЧС ПО ПОВЫШЕНИЮ БЕЗОПАСНОСТИ НА ВОДНЫХ ОБЪЕКТАХ}

На основе проведенного анализа деятельности ФКУ Центра ГИМС МЧС России были выцвлены следуюцие проблемы: неэффективная работа со СМИ, недостаточная информационная оснаиценность официального саитта, отсутствие деятельности в социальных сетях, невозможность в полном объеме оплатить услуги в электронном виде, не обеспечен принцип "Единого окна», несовериенство кадрового обеспечения. В качестве направлений совериенствования деятельности ФКУ Центр ГИМС МЧС России предлагается: провести оптимизачию расходов на рекламу, усовериенствовать официальный сайт, механизм оказания услуг с использованием официального сайта и принциипом "Единого окна», усовериенствовать организацию труда.

Ключевые слова: организация работы органа исполнительной власти, обеспечение безопасности, повышение безопасности.

\section{Elena Kolesnichenko, Yana Radyukova, Dmitry Kolesnichenko IMPROVEMENT OF EMERGENCY ACTIVITIES \\ FOR IMPROVING SAFETY ON WATER OBJECTS}

Based on the conducted analysis of the activities of the of the Center of the Ministry of Emergency Situations of Russia, the following problems were identified: ineffective work with the media, inadequate information equipment of the official site, lack of activity in social networks, inability to fully pay for services electronically, the principle of «Single Window» imperfection of staffing. As the directions for improving the activities of the Center of the Ministry of Emergency Measures of Russia proposes: to optimize advertising costs, to improve the official site, the mechanism for providing services using the official website and the Single Window principle, and to improve the organization of work.

Key words: organization of the work of the executive authority, ensuring security, improving security.

Bведение / Introduction. Деятельность МЧС России представляет собой сложный механизм, взаимодействие составляющих которого важно для поддержания безопасности в стране. ФКУ Центр ГИМС МЧС России для обеспечения безопасности на водных объектах осуществляет следующие виды деятельности: проводит государственную регистрацию и учет м-мерных судов; проводит аттестацию на право управления м-мерными судами; проводит освидетельствование маломерного судна; проводит мероприятия по повышению безопасности на водных объектах.

Цель исследования заключается в том, чтобы на основе анализа существующих теоретических и практических данных разработать пути повышения результативности деятельности по предоставлению государственных услуг на водных объектах Тамбовской области. 